\title{
Effectiveness of preventive home visits in reducing the risk of falls in old age: a randomized controlled trial
}

\author{
Tobias Luck ${ }^{1,2, *}$ \\ Tom Motzek ${ }^{3, *}$ \\ Melanie Luppa' \\ Herbert Matschinger \\ Steffen Fleischer ${ }^{4}$ \\ Yves Sesselmann ${ }^{4}$ \\ Gudrun Roling ${ }^{5}$ \\ Katrin Beutner ${ }^{4}$ \\ Hans-Helmut König ${ }^{6}$ \\ Johann Behrens ${ }^{4}$ \\ Steffi G Riedel-Heller ${ }^{\prime}$ \\ 'Institute of Social Medicine, \\ Occupational Health and Public \\ Health, University of Leipzig, Leipzig, \\ Germany; ${ }^{2}$ Leipzig Research Center \\ for Civilization Diseases, University \\ of Leipzig, Leipzig, Germany; \\ ${ }^{3}$ Technical University Dresden, \\ Dresden, Germany; ${ }^{4}$ Institute of \\ Nursing and Health Science, Martin- \\ Luther-University Halle-Wittenberg, \\ Halle, Germany; ${ }^{5}$ Faculty of Health, \\ Witten/Herdecke University, Witten, \\ Germany; ${ }^{6}$ Department of Health \\ Economics and Health Services \\ Research, University Medical Center \\ Hamburg-Eppendorf, Hamburg, \\ Germany \\ *These authors contributed equally \\ to this work
}

Correspondence: Tobias Luck University of Leipzig, Institute of Social Medicine, Occupational Health and Public Health, Public Health Research Unit, Philipp-Rosenthal-Strasse 55, Leipzig D-04103, Germany

Tel +49 34I 9724568

Fax +49 34I 9724569

Email tobias.luck@medizin.uni-leipzig.de
This article was published in the following Dove Press journal:

Clinical Interventions in Aging

II June 2013

Number of times this article has been viewed

Background: Falls in older people are a major public health issue, but the underlying causes are complex. We sought to evaluate the effectiveness of preventive home visits as a multifactorial, individualized strategy to reduce falls in community-dwelling older people.

Methods: Data were derived from a prospective randomized controlled trial with follow-up examination after 18 months. Two hundred and thirty participants ( $\geq 80$ years of age) with functional impairment were randomized to intervention and control groups. The intervention group received up to three preventive home visits including risk assessment, home counseling intervention, and a booster session. The control group received no preventive home visits. Structured interviews at baseline and follow-up provided information concerning falls in both study groups. Random-effects Poisson regression evaluated the effect of preventive home visits on the number of falls controlling for covariates.

Results: Random-effects Poisson regression showed a significant increase in the number of falls between baseline and follow-up in the control group (incidence rate ratio 1.96) and a significant decrease in the intervention group (incidence rate ratio 0.63 ) controlling for age, sex, family status, level of care, and impairment in activities of daily living.

Conclusion: Our results indicate that a preventive home visiting program can be effective in reducing falls in community-dwelling older people.

Keywords: falls, randomized controlled trial, home visits, prevention, evaluation

\section{Introduction}

Falls in older people are a major public health problem. ${ }^{1,2}$ Approximately $30 \%$ of community-dwelling people aged $65+$ years experience at least one fall per year. ${ }^{3}$ Injuries related to falls are associated with adverse outcomes, such as functional impairment, disability, institutionalization, or death, ${ }^{4,5}$ placing a significant economic burden on health care systems. ${ }^{6,7}$

The causes of falls are complex, including internal factors (eg, medical conditions, such as eye diseases or osteoarthrosis, reduced balance) and external factors (eg, environmental hazards such as poor lighting or tripping hazards) ${ }^{4,8}$ Current evidence indicates that comprehensive, multifactorial, and individualized strategies to assess and reduce numerous such risk factors can be effective in reducing the rate of falls in community-dwelling older people, even though the findings are heterogeneous. ${ }^{9}$

Preventive home visits as an example of such a comprehensive strategy offer the opportunity to identify possible risk factors for falling in an individual's relevant environment and to make recommendations for reducing the risk of falling tailored to this specific environment, which is an important advantage because falls are the leading 
cause of home injury deaths among adults $\geq 80$ years. ${ }^{10}$ However, previous studies did not show clear evidence of the effectiveness of preventive home visits to reduce falls in old age. ${ }^{11-13}$ A systematic review by van Haastregt et al identified two trials showing a significant reduction in the number of falls in an intervention group with preventive home visits as well as four trials without such visits, indicating the need for further evaluation. ${ }^{11}$ Moreover, because complex interventions like preventive home visits may be highly sensitive to the local health system, the generalizability of international results to Germany is limited. ${ }^{14}$

The aim of this study was to evaluate the effectiveness of preventive home visits in reducing falls in a sample of community-dwelling people aged 80 years or older living in Germany. We hypothesized that preventive home visits could be effective in reducing falls over the study period of 18 months.

\section{Materials and methods \\ Study design}

We conducted a prospective, multicenter (cities of Leipzig and Halle), randomized, controlled trial with follow-up examination after 18 months. Participants were randomized to an intervention group or to a control group using balanced blockwise randomization stratified by center. Participants and field researchers could not be blinded to group allocation. However, a statistician not involved in the trial (ie, "blinded") conducted the final statistical analysis and only pseudonymized data were analyzed. We stored personal data on all participants (including name and address) separately from the trial data (both in lockable cabinets in lockable rooms). All personal data were treated confidentially. The ethics committees of the universities of Halle and Leipzig approved the study protocol. Research was carried out in compliance with the Declaration of Helsinki. All subjects gave their written informed consent for participation in the study. The study is registered in the ClinicalTrials.gov registry (NCT00644826). The study design and methods have been described in detail elsewhere. ${ }^{14}$

\section{Recruitment of participants}

We recruited participants from health care settings (general practice, general hospitals) and via mail (general population, with addresses provided by local registration). Patients from general medical practices and general hospitals were screened for eligibility by general practice personnel or liaison nurses on site and subjects of the general population by study personnel via telephone. Participation was dependent on living at home, being aged 80 years or older, and having functional impairment in at least three activities of daily living. The latter criteria were chosen to identify a sample with increased risk for institutionalization and in possible need of preventive home visits. Subjects with insufficient knowledge of the German language, cognitive impairment, an inability to give informed consent, or a level of care higher than 1 (according to German long-term care insurance, see below) ${ }^{15}$ at the time of recruitment were excluded. Eligible subjects who consented to participation in the trial were asked to attend an appointment for baseline assessment by the study personnel.

\section{Primary outcome}

The primary outcome of our trial was the incidence of institutionalization over the study period of 18 months. Institutionalization was defined as permanent admission to a nursing home. Participants with short-term, geriatric, or respite care and those who lived in assisted-living facilities were not classified as institutionalized. ${ }^{14}$

\section{Sample size}

The sample size was calculated according to the primary outcome of incidence of institutionalization. Power calculation $(\alpha=0.05 ; \beta=0.20)$ was based on an assumed institutionalization rate of $20 \%$ (estimation based on findings from previous studies), ${ }^{16,17}$ an absolute reduction of the institutionalization rate from such $20 \%$ in the control group to $7 \%$ in the intervention group, and an estimated dropout rate of $30 \%$.

\section{Study procedure}

\section{Baseline assessment}

Individuals were recruited between August 2007 and July 2008. Standardized interviews were conducted by trained study personnel (psychologist, sociologist, or nurse scientist) with all participants in their homes. We assessed falls in all participants in the intervention and control groups by asking two questions: "Did you fall in the last 12 months?" (yes/no); and if yes, "How often did you fall in the last 12 months?"

Participants in the intervention and control groups were also asked if they were categorized into a level of care according to the German long-term care insurance policy. ${ }^{15}$ A higher level of care indicates a higher need of care (level 1, considerable need; 2 , severe need; 3 , extreme need). Categorization into a level of care is based on the exact extent of care required (eg, level 1 requires need for care in basic activities such as personal hygiene, eating, or mobility for at least 45 minutes a day and total need for care for at least 90 minutes a day). 
Performance in basic activities of daily living (eg, personal hygiene, mobility) of participants in the intervention and control groups was assessed using the Barthel Index ${ }^{18}$ and performance in more complex activities of daily living (eg, using the telephone, handling routine finances) with the Instrumental Activities of Daily Living scale devised by Lawton and Brody. ${ }^{19}$

At baseline, participants in the intervention group (but not in the control group) also underwent a multidimensional geriatric assessment (first preventive home visit) of self-care deficits and risk factors for institutionalization, including those that are also associated with falling (eg, impairment in vision, age-inappropriateness of housing conditions, or malnutrition). ${ }^{14}$

\section{Case review}

Case conferences were held for each participant in the intervention group within three weeks after baseline. Multidisciplinary teams (eg, nurse scientist, psychologist, gerontopsychiatrist) analyzed the identified self-care deficits and risk factors for institutionalization and compiled individualized interventions and recommendations. When necessary, further experts (eg, nutritionist, social worker) were consulted.

\section{Home counseling visit}

Two to three weeks after the first preventive home visit, participants in the intervention group were visited again (second preventive home visit) by the study personnel to address identified self-care deficits and risk factors for institutionalization and present recommendations from the case review. Interventions were carried out through guidance, verbal information, and/or handing out informative materials. Relatives were involved in the counseling process whenever possible. When necessary, participants were also referred to external experts (eg, to an ophthalmologist or optometrist for vision impairment).

\section{Booster session}

One month after the counseling home visit, a third preventive home visit was conducted in the intervention group to evaluate the extent to which the study participants adhered with recommendations given in the second preventive home visit. Obstacles and facilitators to adherence were assessed, recommendations were re-emphasized, and further assistance was provided.

\section{Falls prevention}

The procedures used for geriatric assessment, case review, home counseling visits, and booster sessions to reduce identified self-care deficits and risk factors for institutionalization were also used to address an increased risk of falling. Individualized interventions and recommendations (at the home counseling visit and booster session) were supplemented by general information provided to the participants in the intervention group at the home counseling visit independent of the individual risk of falling, including information on:

- age-related frequency and risk of falling

- causes of falls in older age, eg, visual impairment, decreasing bone density, disabilities in balance and gait, and home hazards (eg, poor lighting, inappropriate footwear, tripping hazards)

- options to reduce the risk of falling and consequent injuries (eg, installing bright lighting, wearing antislip shoes, removing hazards, such as carpet edges, using aids like walkers, muscle strength and balance training, and vitamin D and calcium supplementation).

Participants were also encouraged to check and eliminate possible risk factors for falling with the assistance of their relatives. Participants in the control group received no preventive home visits and thus no interventions for falls.

\section{Follow-up assessment}

Eighteen months after baseline, standardized follow-up interviews were conducted by study personnel with all participants in their homes (follow-up period, January 2009 to February 2010) to evaluate the preventive home visits. Follow-up interviews included the same assessment as the baseline interviews.

\section{Statistical analysis}

The statistical analysis was performed with PASW for Windows version 20.0 (IBM Corp., Armonk, NY, USA) and Stata version 11.0 (StataCorp LP, College Station, TX, USA). All analyses employed an alpha level of 0.05 for statistical significance (two-tailed). We analyzed group differences using the Mann-Whitney $U$ test and $\chi^{2}$ test as appropriate. Random-effects Poisson regression ${ }^{20}$ estimating incidence rate ratios and $95 \%$ confidence intervals was used to evaluate the effect of preventive home visits on the number of falls, controlling for covariates. We used this method because the dependent variable (number of falls) is a count variable and the interindividual (between) differences are modeled by the random part. Moreover, we used the Hausman test to check the random-effects Poisson regression model against a random-effects negative binomial model that can also be applied to model counts. ${ }^{21}$ The Hausman test did not show a signifi- 
cant difference between the models $\left(\chi^{2}=6.91, P=0.734\right)$, so we only showed the results of the Poisson regression model. Selection of covariates was hypothesis-driven.

\section{Results}

\section{Participants}

Of the 336 subjects screened for eligibility, 31 (9.2\%) were excluded for the reasons shown in Figure 1. The remaining 305 participants were randomized in study groups (ie, control group, $\mathrm{n}=155$; intervention, $\mathrm{n}=150$ ). Of the total 305 participants, 75 (24.6\%) dropped out of the study before follow-up examination or were excluded. Evaluation of the effectiveness of preventive home visits in reducing falls in community-dwelling older people was based on the remaining 230 participants (control group, $\mathrm{n}=112$; intervention group, $\mathrm{n}=118$ ). The 75 participants who dropped out of the study or were excluded from the analyses did not differ significantly from the 305 participants who were included in terms of number of falls ( 1.9 versus $1.9, P=0.766)$, age ( 85.9 versus 85.1 years, $P=0.130$ ), or sex (women, $72.0 \%$ versus $67.4 \%, P=0.455)$.

Among those included in the analyses, subjects in the control group did not differ significantly from those in the intervention group in terms of mean age at baseline $(85.2 \pm 3.5$ years versus 85.4 \pm 3.6 years; Mann-Whitney $U$ test $=11,374.500$; $P=0.745$ ) or sex (women, $71.6 \%$ versus $65.3 \% ; \chi^{2}=1.394$; $\mathrm{df}=1 ; P=0.238)$. The mean number of falls in the 12 -month study period was also similar in both groups at baseline $(1.9 \pm 1.7$ versus 1.9 \pm 5.7 ; Mann-Whitney $U$ test $=1,139.000$; $P=0.179$ ), but significantly higher in the control group than in the intervention group at follow-up $(3.7 \pm 4.2$ versus $2.2 \pm 2.5$; Mann-Whitney $U$ test $=662.000 ; P=0.007)$.

\section{Multivariate analysis of effect of preventive home visits on falls}

Random-effects Poisson regression showed a significant increase in the number of falls from baseline to follow-up in the control group (incidence rate ratio 1.96) and a significant decrease in the intervention group (incidence rate ratio 0.63 ) after controlling for age, sex, family status, care level, and degree of impairment in basic and instrumental activities of daily living (see Table 1). The difference between the courses of the two groups (reported as difference 1 and 2 in Table 1) was significant.

The number of falls was also significantly affected by the degree of impairment in basic activities of daily living (incidence rate ratio 0.97; the higher the impairment in basic activities of daily living, the higher the number of falls). No

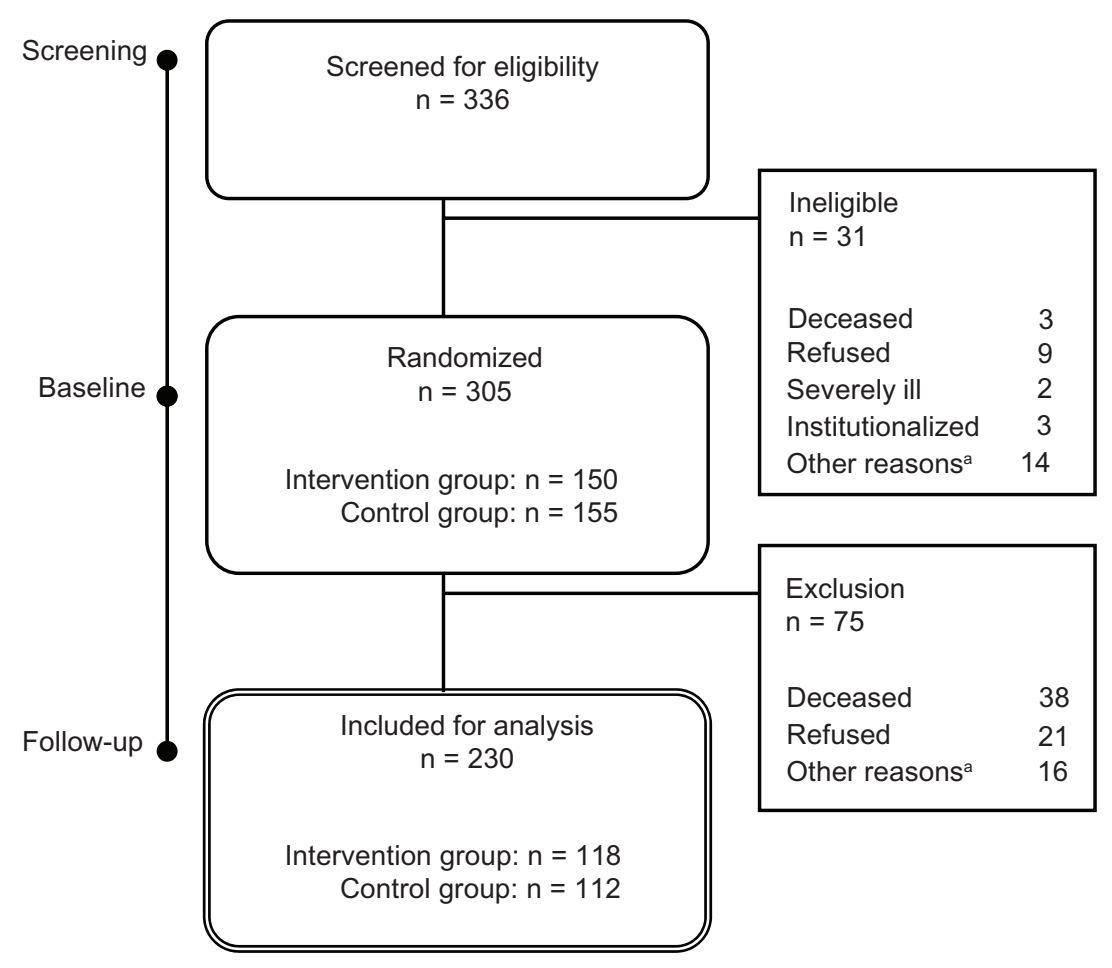

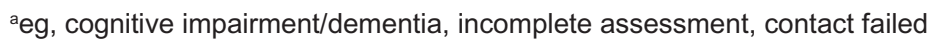

Figure I Sample attrition and sample. 
Table I Random-effects Poisson regression a evaluating the effect of preventive home visits on the number of falls

\begin{tabular}{|c|c|c|c|c|c|c|}
\hline & IRR & SE & $\mathbf{z}$ & $\mathbf{P}>|\mathbf{z}|$ & $95 \%$ & \\
\hline I. Control group (BL to FU) & 1.96 & 0.29 & 4.50 & $<0.001$ & 1.46 & 2.63 \\
\hline $\begin{array}{l}\text { 2. Intervention group } \\
\text { (BL to } F U)\end{array}$ & 0.63 & 0.10 & -2.96 & 0.003 & 0.47 & 0.86 \\
\hline $\begin{array}{l}\text { Baseline differences } \\
\text { between CG and IG }\end{array}$ & 1.54 & 39 & 0 & 0.089 & 94 & 2 \\
\hline Differenc & 0.32 & 0.07 & -5.44 & $<0.001$ & 0.22 & 0.49 \\
\hline Age, e & 0.96 & 0.03 & -1.05 & 0.2 & 0.90 & 1.03 \\
\hline $\operatorname{Sex}(\mathrm{fe}$ & 0.92 & 0.25 & -0.32 & 0.750 & 0.54 & 1.55 \\
\hline II & 0.82 & 0.18 & -0.90 & 0.368 & 0.53 & 1.27 \\
\hline $\begin{array}{l}\text { Care level } 2 \\
\text { (versus no care level) }\end{array}$ & 0.50 & 0.22 & -1.54 & 0.124 & 0.21 & 1.21 \\
\hline Family status $^{c}$ & 0.87 & 0.21 & -0.60 & 0.550 & 0.55 & 1.38 \\
\hline BADL sum score & 0.97 & 0.01 & -4.47 & $<0.001$ & 0.96 & 0.98 \\
\hline IADL sum score & 0.93 & 0.05 & -1.35 & 0.177 & 0.83 & 1.04 \\
\hline
\end{tabular}

Notes: aLikelihood ratio test: $\chi^{2}=534.08, P<0.001$; ${ }^{b}$ differences in the courses (from baseline to follow-up) between the two groups; 'single/widowed/divorced versus married.

Abbreviations: BADL, basic activities of daily living (the higher the sum score, the lower the impairment); $\mathrm{BL}$, baseline; $\mathrm{CG}$, control group; $\mathrm{Cl}$, confidence interval; FU, follow-up; IADL, instrumental activities of daily living (the higher the sum score, the lower the impairment); IG, intervention group; IRR, incidence rate ratio; SE, standard error.

significant impact on falls was found for age, sex, nursing care level, family status, or impairment of instrumental activities of daily living.

\section{Discussion}

Our results indicate that preventive home visits can be effective in reducing falls in community-dwelling older people. The findings corroborate results from a previous randomized controlled trial that was also conducted in Germany, ${ }^{22}$ which reported $31 \%$ fewer falls after one year in an intervention group that received comprehensive geriatric assessment followed by a diagnostic home visit and home intervention compared with a control group that received comprehensive geriatric assessment with recommendations but usual care at home (incidence rate ratio 0.69). Moreover, our results are consistent with the findings of a Cochrane review reporting overall evidence for the effectiveness of multifactorial interventions in reducing the rate of falls in community-dwelling older people (incidence rate ratio $0.75,95 \%$ confidence interval $0.65-0.86) .{ }^{9}$

However, a significant number of studies have failed to demonstrate the effectiveness of preventive home visits in reducing the risk of falls. ${ }^{11-13}$ As stated above, the systematic review reported by van Haastregt et al identified two trials showing a significant reduction in the number of falls in an intervention group with preventive home visits and also four trials not showing any effect of intervention. ${ }^{11}$ The main disadvantage of the preventive home visiting strategies identified by van Haastregt et al and by other researchers is the difficulty in distinguishing the effective components of such a complex and multidimensional intervention from the total set of components. ${ }^{11,12}$ Even though we also could not make such a distinction, we suggest that the effectiveness of preventive home visits in our study might be attributed to a combination of factors:

- multidimensional geriatric assessments in participants' homes enabled identification of a broad range of possible internal and external risk factors for falling

- multidisciplinary case reviews enabled comprehensive evaluation of the risk factors identified and development of interventions tailored to the individual's situation

- a combination of individualized interventions and recommendations for participants at risk (secondary prevention) and provision of general information to the participants in the intervention group independent of the risk of falling (primary prevention)

- a final preventive home visit to emphasize recommendations, remove obstacles, and provide further assistance, and thereby increase compliance.

Our study may be of particular interest because its findings confirm the effectiveness of preventive home visits in a sample of community-dwelling people who were quite elderly (aged 80 years or older, mean age 85.1 years), and so had a considerably increased risk of falling as well as institutionalization.

However, our study is not without limitations. First, the sample size was not calculated according to the outcome of falls, although it had sufficient power to detect a significant effect of preventive home visits on this outcome. Second, falls were assessed retrospectively by asking only two questions. A number of falls studies alternatively or additionally used prospective calendar self-reports to assess occurrence of falling and the number of falls..$^{12,13,23}$ With regard to the findings of a validation study by Mackenzie et al, a retrospective self-report such as that used in our study was found to be less sensitive (56\%) and less specific (94.7\%) than the prospective calendar method for assessment of falls over a six-month period. ${ }^{23}$ Therefore, our data may be afflicted with some degree of inaccuracy. Third, participants and field researchers could not be blinded to group allocation. Fourth, only $21.3 \%$ of the participants in the intervention group completely followed the individualized recommendations for fall prevention (7.4\% followed partially, $2.8 \%$ reduced their risk of falling using other strategies, and $25.9 \%$ refused to follow the individualized recommendations). Another $38.0 \%$ of participants 
stated that they felt well informed and intended to follow the individualized recommendations when it became necessary (ie, higher perceived risk of falling) in their own view (data on acceptance/refusal of recommendations for the remaining $4.6 \%$ of the participants could not be collected). However, fall prevention in the trial not only included individualized interventions and recommendations, but also provision of general information, eg, on causes of falls or on strategies to reduce the risk of falling and consequent injury. Even if participants did not follow the specific recommendations, the risk of falling might also have been reduced by the general information provided, eg, a change in behavior because of raised awareness about the underlying causes of falls. Finally, although the preventive home visits seemed to be effective in reducing falls, they were time-consuming and resourceconsuming, so might not be cost-effective.

To improve the cost-effectiveness and outcomes of preventive home visits in reducing falls, further research should focus on identification and facilitation of the components of a preventive home visit program in the target group that could benefit most. ${ }^{4,24}$

\section{Acknowledgment}

This work was supported by grants from the German Federal Ministry of Education and Research (01GT0601, 01GT0604) as part of the German Nursing Research Network.

\section{Disclosure}

The authors report no conflicts of interest in this work.

\section{References}

1. Hanley A, Silke C, Murphy J. Community-based health efforts for the prevention of falls in the elderly. Clin Interv Aging. 2011;6:19-25.

2. Soriano TA, DeCherrie LV, Thomas DC. Falls in the communitydwelling older adult: a review for primary-care providers. Clin Interv Aging. 2007;2:545-554.

3. Lord SR, Sherrington C, Menz HB, Close JCT. Falls in Older People: Risk Factors and Strategies for Prevention, 2nd ed. Cambridge, UK: Cambridge University Press; 2006.

4. Kannus P, Sievänen H, Palvanen M, Järvinen T, Parkkari J. Prevention of falls and consequent injuries in elderly people. Lancet. 2005;366: 1885-1893.

5. Michael YL, Whitlock EP, Lin JS, et al; US Preventive Services Task Force. Primary care-relevant interventions to prevent falling in older adults: a systematic evidence review for the US Preventive Services Task Force. Ann Intern Med. 2010;153:815-825.
6. Davis JC, Robertson MC, Ashe MC, Liu-Ambrose T, Khan KM, Marra CA. International comparison of cost of falls in older adults living in the community: a systematic review. Osteoporos Int. 2010;21:1295-1306.

7. Heinrich S, Rapp K, Rissmann U, Becker C, König HH. Cost of falls in old age: a systematic review. Osteoporos Int. 2010;21:891-902.

8. Carter ND, Kannus P, Khan KM. Exercise in the prevention of falls in older people: a systematic literature review examining the rationale and the evidence. Sports Med. 2001;31:427-438.

9. Gillespie LD, Robertson MC, Gillespie WJ, et al. Interventions for preventing falls in older people living in the community. Cochrane Database Syst Rev. 2009;2:CD007146.

10. Mack KA, Rudd RA, Mickalide AD, Ballesteros MF. Fatal unintentional injuries in the home in the US, 2000-2008. Am J Prev Med. 2013;44: 239-246.

11. van Haastregt JC, Diederiks JP, van Rossum E, de Witte LP, Voorhoeve PM, Crebolder HF. Effects of a programme of multifactorial home visits on falls and mobility impairments in elderly people at risk: randomised controlled trial. BMJ. 2000;321:994-998.

12. Hogan DB, MacDonald FA, Betts J, et al. A randomized controlled trial of a community-based consultation service to prevent falls. CMAJ. 2001;165:537-543.

13. Mahoney JE, Shea TA, Przybelski R, et al. Kenosha County falls prevention study: a randomized, controlled trial of an intermediate-intensity, community-based multifactorial falls intervention. J Am Geriatr Soc. 2007;55:489-498.

14. Fleischer S, Roling G, Beutner K, et al. Growing old at home - a randomized controlled trial to investigate the effectiveness and cost-effectiveness of preventive home visits to reduce nursing home admissions: study protocol [NCT00644826]. BMC Public Health. 2008;8:185.

15. The German Federal Ministry of Health. [Levels of care]. Available from: http://www.bmg.bund.de/pflege/wer-ist-pflegebeduerftig/ pflegestufen.html. Accessed April 16, 2013. German.

16. Bickel $\mathrm{H}$. The last year of life: a population-based study on decedents. Living arrangements, place of death, and utilization of care. Z Gerontol Geriatr. 1998;31:193-204. German.

17. Wilms HU, Riedel-Heller SG, Busse A, Angermeyer MC. Need of help and care in old age in the former East German states: results from the Leipzig longitudinal study of the aged population (LEILA75+). Z Gerontol Geriatr. 2001;34:348-355. German.

18. Mahoney FI, Barthel DW. Functional evaluation. The Barthel Index. Md State Med J. 1965;14:61-65.

19. Lawton MP, Brody EM. The Instrumental Activities of Daily Living Scale. Gerontologist. 1969;9:179-186.

20. Cameron AC, Trivedi PK. Regression Analysis of Count Data. Econometric Society Monographs. Cambridge, UK: Cambridge University Press; 1998.

21. Hausman JA. Specification tests in econometrics. Econometrica. 1978;46:1251-1271.

22. Nikolaus T, Bach M. Preventing falls in community-dwelling frail older people using a home intervention team (HIT): results from the randomized Falls-HIT trial. J Am Geriatr Soc. 2003;51:300-305.

23. Mackenzie L, Byles J, D ‘Este C. Validation of self-reported fall events in intervention studies. Clin Rehabil. 2006;20:331-339.

24. Close JC. Prevention of falls - a time to translate evidence into practice. Age Ageing. 2005;34:98-100.
Clinical Interventions in Aging

\section{Publish your work in this journal}

Clinical Interventions in Aging is an international, peer-reviewed journal focusing on evidence-based reports on the value or lack thereof of treatments intended to prevent or delay the onset of maladaptive correlates of aging in human beings. This journal is indexed on PubMed Central, MedLine, the American Chemical Society's 'Chemical Abstracts

\section{Dovepress}

Service' (CAS), Scopus and the Elsevier Bibliographic databases. The manuscript management system is completely online and includes a very quick and fair peer-review system, which is all easy to use. Visit $\mathrm{http}: / /$ www.dovepress.com/testimonials.php to read real quotes from published authors. 